\title{
Reviews
}

The Person and the Challenges

Volume 6 (2016) Number 1, p. 263-273

DOI: http://dx.doi.org/10.15633/pch.1670

Pauline Dimech

University of Malta

\section{Extracting the Creativity Within: A Review of Education and Creativity, edited by Elżbieta Osewska}

One would expect a book with such a title - Education and Creativity - to be about pedagogy within a school context, which it is not ${ }^{1}$. Or rather, it is much more than that. Although essays such as Stanko Gerjolj's on emotional, moral and religious intelligences deal specifically about the class community, the book is not just about schools. Thankfully, the word education, which appears in the title, is used more broadly. So is the word creativity. Creativity is mostly understood as discovery, or as the innovative re-combination of ideas, but it is also linked to dialogue and communication. Naturally, there is, within the book as a whole, an evident attempt on the part of the editor, to establish the relationship between creativity and education. Throughout the book, the reader learns about creativity within the field of education, about creative teaching, about creative learning, and about creative learning environments. We are also made to reflect upon teaching for creativity, learning for creativity, the relationship between different kinds of intelligences and creativity, as well as upon the more practical possibility of establishing a policy of creativity in education, and of introducing the education

${ }^{1}$ E. Osewska (Ed.), Education and Creativity, Wydawnictwo Uniwersytetu Kardynała Stefana Wyszyńskiego, Warszawa 2014. 
of creativity within the curriculum. The book also participates in the current conversation concerning the role of various individuals: teachers, pedagogues and parents, in developing the creativity of pupils, as well as the role of various educational settings (family, parish, clubs, and other institutions) where creativity is concerned.

Most would agree that there exist specific skills and specific methods which can contribute to creativity, and which can be discovered, but also that an interdisciplinary and international context is necessary in order to establish the value of creativity, discover what enhances it, as well as to apply the right techniques to increase it. The editor plainly acknowledges all of this. Where creativity is concerned, we are made to reflect on the role of the emotions, the role of the imagination, the role of personal relationships, the role of art, and also upon the role of spirituality. As it is to be expected, the role of information and communication technology takes some precedence within the book as a whole, so that the first section of the book is dedicated to it. You could say that the media as a subject persists throughout the whole book, and the authors keep coming back to it. One common point of agreement among the contributors is their emphasize on the importance of a critical evaluation of the media and of the values and assumptions which the media conveys.

In her essay on 'Education and Internet Challenges', Elżbieta Osewska ascribes the creativity of pupils to ICT, or rather interprets ICT as an important trigger of creativity. It is emphasized that ICT provides a new understanding of teaching and learning. More specifically, it is claimed that ICT offers new possibilities for students to be creative learners, to generate and try out ideas, to participate and communicate, to create communities, for learners to take responsibility for their learning, for teachers to be creative teachers, and so on. Here, learning is interpreted as a management process: the learner's role is to manage the complex process of sifting through resources. In addition, ICT is understood as an interaction technology not just as information technology. The author explores the implications of individual access to the internet. In her view, here, it is the students who set the route, there are new ways of engaging in education, new types of knowledge, new competences, new approaches, which then result in new ways of behaving (in new computer-related behaviours), in a new understanding of what it means to be knowledgeable. According to Osewska, even a new meaning to life emerges as a consequence of ICT.

Osewska also hints at some of the consequences of ICT to evangelization and to Religious education in particular. Her argument is that ICT culture 
changes the status of convictions, reflections and conclusions. Information becomes relative, changeable, or even manipulative. Her emphasis on the issue of community is especially significant: ICT provides new ways of being community. Osewska's emphasis on the necessity of examining the internet from a theological, pedagogical and catechetical perspective should not go unheeded. It has huge implications for evangelization and for Religious education. Her essay takes on a somewhat exhortative tone. She contends that creativity is essential, if educators are to go beyond the development of technology to an integral human development, and if they are to create the proper cultural environment for religious sensitivity, faith, practice. Above all, educators must train students in the use of the internet ${ }^{2}$.

Erika Prijatelj deals more specifically with what is called the 'logic' of the spectacle. She argues that we are surrounded by spectacles. Even everyday life and culture is being turned into entertainment. Prijatelj claims that these media spectacles embody the basic values of modern society; values which enable us to analyse our existence, as well as to define our social relationships. The author compares Guy Debord and Douglas Keller on the spectacle. She then goes on to explore the preference for virtual reality, as well as the neglect of one's own life which occurs because of dissatisfaction and an absence of creative energy. I would have liked to read more about the effect of these spectacles on young people and on children, as well as to see more emphasis on how the scholastic context may respond to them. The fact that education also takes place within the theatre and on TV does not eliminate the fact that the school is an important context for education, and a place where the influence of reality shows and of spectacles is as powerful, if not more, than it is in other institutions, and with other age groups. Still, Prijatelj does challenge us when she identifies some of the general effects of reality shows. We are told how these shows create a new view of intimacy and a new way of communicating, how they serve as a different context where public debates and social discussions are held, how these reality shows give rise to the cult of health and the worship of the body. Prijatelj also explores the significance of Sports broadcasts, and she reflects on the explicitness of violence, and on the promotion by the media of values such as self-indulgence, reputation, power, selfishness, pleasure, narcissism and irresponsibility, to the detriment of the intellectual, the cultural, the aesthetic and the spiritual. According to Prijatelj, the media avoids the more existential question of the meaning of life

${ }^{2}$ E. Osewska, Education and Internet Challenges, p. 43-56. 
or of the purpose of human tasks, so that there is a vacuum where the more existential issues are concerned. The author also claims that the 'creativity in spectacle has subordinated people proportionally to their subordination to the economy'. She argues that, as people look for more easily accessible pleasures, they become less creative. Moreover, she maintains that the satisfaction that ensues from such spectacles is generally artificial. The author thus emphasizes the more negative influences of the media, and particularly of Theatre productions. She claims that there has been a shift from unity and cohesion to separation and fragmentation, as well as that localised neighbourhoods have been eliminated. According to her, the interaction generated by the media is not necessarily creative. She points out that the media merely provide information and data, and that there is a huge difference between problem-solving and creating something ${ }^{3}$.

On their part, Amy Lee and Rhiannon D. Williams provide a description of their own project, involving a diverse group of students, and an activity which engages this diversity. The emphasis is mostly on the advantages of using experiential pedagogical tools. Lee and Williams argue that the frequency and features of intercultural interactions has an effect on the quality of these intercultural interactions. They maintain that, when the student group is diverse, when the classroom environment is diverse, and when the course content and pedagogy are also diverse, the possibility of having a positive outcome becomes greater ${ }^{4}$. The implication seems to be that the level of diversity has a direct effect on the quality of the creativity.

Janusz Mastalski's essay is placed in the second part of the book, dealing with creativity and catechesis. Mastalski's essay is more specifically directed to the self-improvement of the individual catechist, especially where the creativity of the catechist is concerned. The author describes creativity as a 'process in which new concepts and ideas emerge', as well as a personality and human faculty that some people have. Mastalski emphasizes how essential creativity is, and identifies the main characteristics of creative people, namely, courage, strength to overcome, humour and intuition. He also uses A.Murdoch's fundamental principles of creative people. He then focusses on teacher creativity in particular. He uses various experts to elicit a number of characteristics of creative teachers, namely, reflectivity, care of authority, enthusiasm, good organisation, an

${ }^{3}$ E. Prijatelj, Creativity and Values in the Media Culture of Today, p. 57-66.

4 Amy Lee and Rhiannon D. Williams, Designing Intercultural Interactions: Students' Reflections on a Personal Narrative Assignment, p. 67-76. 
integrated vison of oneself, cooperation with other teachers, self-criticism, and multi-faceted self-enrichment. Mastalski asserts that creativity must be cultivated along with the two qualities which Pope John Paul II had emphasized, namely, a theological preparation and a knowledge of the humanities. Mastalski singles out five dimensions of creativity for the catechist, namely, that of personality, the spiritual, the didactic, the intellectual and the ecclesial. Finally, Mastalski devises a $5 \mathrm{X}$ S rule, providing five specific imperatives (shoulds) that can contribute to an increase in personal creativity. I found these shoulds a little too self-scrutinizing, and I would have liked to see a more social perspective, where it is the whole teaching community which seeks to be creative. Moreover, with Mastalski, it seems that creativity only belongs to the few, although it can be cultivated, and should be cultivated, in others ${ }^{5}$.

One of the things which is quite unique about this book on Education and Creativity is actually that we have a theological interpretation of creativity. Patricia Kieran's essay emphasises that creativity arises from a person's uniqueness and connection with God. Kieran very skilfully combines the theological with the educational, as well as the theoretical with the pedagogical. She begins with a reference to the book of Genesis, and claims that the imago Dei also comprises a resemblance of humanity to the divine that takes the form of a capacity to create. So, creativity is interpreted as a human attribute that make humanity analogous to God. Being a child of God comes with a call to creativity. Kieran thus links the theological concept of creation with the educational concept of creativity, presenting her readers with an analogy, whereby human beings are similar to God in being co-creators, but different, in that human creativity is very much unlike divine creativity. Kieran also delves into the relationship between the two. She also argues that all human beings are creative artists, although they may not be exceptionally creative people, as John Paul II had said. Whereas Mastalski could be accused of limiting creativity to the few, by claiming that every human being is a creative presence, Kieran seems to reduce creativity to a transcendental quality of being. Although I myself chose to use the term 'extracting' in the title because of the etymology of the term 'education', from the Latin 'educere', meaning to extract, and although many would claim that the creative is already present within the individual and is waiting to come out, with this view, there is the risk of perceiving creativity as a universal, and thus a commonplace quality that is no longer remarkable. Kieran also claims that

${ }^{5}$ J. Mastalski, Creative Catechist, That Means Who?, p. 77-86. 
creativity is very subjective. She argues that there are multiple interpretations and expressions of creativity, without claiming that all interpretations and expressions of creativity are equal. Kieran uses the Alive $O$ programme to give concrete examples of creative methods used with younger children. These include pottery and juggling balls. Kieran emphasises the creativity that characterises the activity of teaching itself, particularly because of the inherent unpredictability of this activity. Kieran is also, I believe, the only one who writes about blocks and impediments to creativity. Most importantly, Kieran discusses creativity and Religious education as well as creativity and Catechesis. She maintains that it is not simply the use of digital resources that make Religious Education creative, but that it is the whole process of Religious education that should be seen as creative. It fosters creativity by encouraging 'learners to explore, reflect and respond to' experience and life ${ }^{6}$. On the other hand, 'great catechists are inspired with the spirit of creativity" ${ }^{7}$. Such creativity, which is made evident when the catechist thinks deeply about the message, and cares passionately for his listeners, remains a challenge for all catechists ${ }^{8}$.

Adrian Gellel begins his essay by pointing out that more often than not, religious education does not feature within educational journals, as well as that academics within the field of Religious education often fail to use the educational sciences in their own research. He claims that this side- lining of Religious Education is a consequence of its very nature, requiring the input of both theology and the Educational sciences. With Prof Gellel, the more significant educational sciences seem to be Educational Psychology and Instructional Design. Gellel also expresses agreement with M. J. Lee, in claiming that the didactic method and the content are inseparable. Having made these statements, Gellel then goes on to describe the A.R.E method, claiming that Adaptive Religious Education has its roots in tradition, with various Christian philosophers and theologians having reflected on individual differences and on dealing with these differences in an educational context. Gellel's emphasis is on the optimization of the student's potential, rather than on equity. Gellel expresses agreement with Cronbach in that he identifies a division between experimental psychology and correlational psychology. He proposes further research which would unite the study of variance among individuals and the variance among treatments (Aptitude-

\footnotetext{
6 P. 97.

7 P. 99.

${ }^{8}$ P. Kieran, Divine Creativity and the Creative Art of Catechesis, p. 87-104.
} 
-Treatment Interaction: ATI). He also asserts that lessons are often prepared on the basis of the intuition and the experience of the teacher, rather than on actual empirical research, and expresses regret that this is the case. Gellel claims that more empirical research on the interaction between aptitude and situational complexes ought to be carried out. In this essay, Gellel expounds the principles of the A.R.E. method and, in particular, the use of differentiated methods which manoeuvre the learning situation in order to adapt to the students' propensities. This is a method that demands creative imagination and resourcefulness. Gellel identifies some of these methods, which he divides according to whether the symbol system is verbal, visual or concrete, claiming that teaching techniques should exploit all symbol systems ${ }^{9}$.

Next follows one of the more provoking essays in this volume: that by Józef Stala. Stala provides an overview of RE in state schools in Poland. His essay is specifically about what has been called 'the New Approach' to RE. Stala explains how, in collaboration with Prof Osewska, he has been responsible for the production of a set of children's Religious Education books, a process which involved parents, grandparents, guardians, and educators, but focussed on the recognition that children's experience and way of communication is particular, that it is possible to theologize with children, that it is possible to respond to children's questions concerning existence and the character of God, that the child is a theologizing subject, that the family is a learning community, that adults and children are mutual in their search for God, that the role of the teacher is that of facilitator. Stala claims that what makes these books so relevant is that children were involved throughout the entire process of the production of the books, without neglecting the objective presentation of faith. For Stala, children are theologizing subjects and Stala maintains that our question should not be: what is the appropriate method for teaching the orthodox truth successfully, but rather, how do we create a cultural environment which would lead to a religious sensitivity, which would enable us to discover what faith in the living God stands for and which would help us understand what believers mean when they practice their faith. Stala also provokes a number of questions concerning faith and education, namely whether faith can generate and justify an understanding of an educational process, whether faith can extend beyond concerns for its own transmission and become the partner of an education concerned with

9 A. Gellel, Adaptive Religious Education: A Scientific Way of Being Creative and Effective in Religious Education, p. 105-116. 
the growth of young people into maturity. In the course of his argument Stala mentions a number of methods which could be applied within the classroom: particularly those requiring the use of critical and creative thinking, the fantasy and the imagination. He maintains that the role of classroom teaching is not to provide emotional experience, as some would insist, but rather to help students identify their experiences and think about them ${ }^{10}$.

The main part of the last section of the book is taken up by a long essay by Graham Rossiter. Rossiter claims to provide an innovative evaluation of the spiritual and moral dimension within the contemporary consumerist lifestyle. What is innovative is that his evaluation focusses on visual imagery, or what he calls 'iconography'. He claims that visual imagery makes meaning. It proposes values and beliefs. Rossiter undertakes at least five things: firstly, to compare contemporary secular spirituality with traditional medieval Christian spirituality. Secondly, to explore the two significant developments during the $20^{\text {th }}$ Century which have resulted in significant changes in the way in which $\mathrm{RE}$ is done, namely, secularisation and the development of approaches to the study of religions within schools that do not have the handing on of the religious tradition as the main objective. Thirdly, to provide a way of interpreting the spirituality within the contemporary lifestyle by using film, a useful exemplar of visual iconography. Fourthly, to propose a new RE pedagogy which makes extensive use of visual materials.

Whereas traditional approaches would track a particular religious tradition, or study a variety of world religions, the pedagogy which is being proposed by Rossiter explores the spiritual and moral dimensions to contemporary living. The perspective is no longer exclusively religious, and there is no reference to organized religion. Rossiter claims that the concept of 'mise-en scéne' from the media world can help us investigate spirituality, most particularly, to enhance our understanding of contemporary secular spirituality ${ }^{11}$.

Rossiter begins his second essay by applying a comparative model. Medieval society is compared to contemporary society. Rossiter claims that, within the current consumerist society, the contemporary story tellers: film, television

${ }^{10}$ J. Stala, RE Books as a Support for Creative Teaching and learning in a Polish Context, p. 117-132.

${ }^{11}$ G. Rossiter, Decoding the Iconography of Contemporary Lifestyle: Uncovering and Evaluating the Spirituality in Consumerist Culture. Part 1: Context, approach and Relevant Literature, p. 133-150. 
and ICT, have replaced religious narratives and texts, the music video has replaced the bells and the hymns, celebrities and stars have replaced the saints, the Brands and the Outlet Centres have replaced relics and pilgrimages, continuous digital engagement has replaced prayer and silence. The talk-show hosts have replaced the priests, the sacramentality of the prestigious branded products have replaced the sacraments, the window shops have replaced the Blessed Sacrament, consumerist feasts have taken over the Christian feasts, consumerist indulgences have replaced religious indulgences, our visits to the shops and stores have replaced the Stations of the Cross, the retail sales have replaced the novenas, the emphasis on the now has replaced the emphasis on the afterlife, individualistic attempts to construct meaning for oneself have replaced the meaning and the sense of belonging which the Church used to provide, the efforts to enhance and maintain one's image and status have replaced the good life with heaven intended as its reward. Thus, whereas Prijatelj asserts that the media avoids the more existential question of the meaning of life or of the purpose of human tasks, and that there is a vacuum where the more existential issues are concerned, Rossiter would say that, within the media, existential answers are implied, if not explicitly stated.

Moreover, Rossiter maintains that there is a worldview which underlies all of these narratives, and that this worldview influences the personal mise-en-scéne. There is, he claims, an implied spirituality even within the modern mise-en-scéne, because of the values and meaning about life which are implied by it. However, because individuals themselves would not attribute their lifestyle to any underlying spirituality, Rossiter suggests that educators should explore with their students 'the existential quality of contemporary spirituality', that is, they should identify the values and meanings which are implied in their lifestyle ${ }^{12}$. A Religious education based on this viewpoint would focus on the implicit religious component within personal and social issues, rather than on religions or on one religion. Rossiter maintains that, if students are to be helped in this process, RE teachers have to develop a critical hermeneutic towards the media and towards the ability of its imagery to shape the mise-en-scéne or meta-narrative which underlies our lifestyle. An essential component of RE would,

${ }^{12}$ G. Rossiter, Decoding the Iconography of Contemporary Lifestyle: Uncovering and Evaluating the Spirituality in Consumerist Culture. Part 2: Contrasting the Mise-en-scène of Medieval Christian Spirituality with that of Contemporary Consumerist Lifestyle: Sociological and Educational Implications, p. 151-188. 
according to Rossiter, be the critical interpretation and evaluation of cultural meanings, and the role of the educator would, in Rossiter's words, be that of helping the students to 'detect, identify and articulate the spiritual dimension'. While agreeing with Rossiter that such a task is necessary and urgent, I would have to say that, firstly, it would be a pity if RE were reduced purely to this critical reflection on the messages of the media. RE should do more than that. Secondly, it would be a pity if it was only RE that took this task upon itself. This ought to be the task of the whole of the education system. In spite of everything, I am truly thankful for the enlightening essays produced by Rossiter.

Brendan Reed provides a summary of the issues facing Catholic parishes and religious groups in Australia. He expresses particular interest in the Parish's response to these challenges and in particular in the way in which parishioners see the purpose and mission of their parish. He writes about a pastoral instrument which he has been working on himself, which, he claims could furnish parishes and pastoral workers with a framework and a tool for understanding their contemporary cultural context with SPES (Searching for Parish Engagement Scale), inspired by the work done in the Enhancing Catholic School Identity Project (ECSIP) ${ }^{13}$. SPES seeks to find out how parishes actually see themselves at the factual level, as well as how they see their ideal parish in the future on the normative level. Reed describes how the empirical normative position is compared to the SPES theological normative position, leading to sociological analysis, but also to theological and pastoral reflection.

Reed provides a very interesting addition to the SPES framework by assigning a parish type to each of the four possible combinations. Parishes would be situated according to where the parishioners see themselves and their parishes in relation to the public-private axis as well as the proclamation-dialogue axis. All four parish types (the 'Convinced', the 'Engaged', the 'Consumerist' and the 'Devoted') are described and evaluated by Reed, who claims that these act as models, thus throwing light and providing insight on reality. I found this essay

${ }^{13}$ The ECSIP explored the types of Catholic schools which are emerging today in a changed and changing western cultural environment, as well as the support which exists in Catholic school communities to continue the task of education from within a Catholic perspective. ECSIP came up with diagnostic tools and a questionnaire which enable the school to compare the perceived actual identity and the hoped for or ideal identity, the 'empirical normative level'. The project has also developed a theological position for a Catholic school to work towards. Cf. B. Reed, Searching for Parish Engagement Scale (SPES), in: E. Osewska (Ed.), Education and Creativity, Wydawnictwo Uniwersytetu Kardynała Stefana Wyszyńskiego, Warszawa 2014. 
to be very interesting, but I would have loved to see at least some attempt at an application of these parish models to a more specifically educational context. I would think that these models could be applied to identity different RE teacher-types, and different philosophies behind RE curricula ${ }^{14}$.

To conclude, as is evident from this review, besides the material that is directly related to education and to creativity, the book contains some very creative reflections on the evolution of secular spirituality, on the mixture of religious and secular elements within spirituality, on the influence of the media on our meta-narrative, on how the media affects the way we think about life in general, on the Parish as an educational context. The book also contains some interesting suggestions concerning the use of techniques in the service of RE. What the book lacks, in my opinion, is a direct contribution from sociologists, and psychologists about education and creativity, as well as feedback from other areas of the world, like Asia, South America and Africa. I would also have liked to see more specific pedagogical proposals concerning creativity within the school, and particularly within RE. Moreover, I have to admit that I could not always see the direct association either to education or to creativity. I certainly cannot say this of the renovated 'Chapel of the Disclosure' described by Herman Lombaerts and translated by Brian Doyle, where the association both with education and with creativity is very clear. I loved this short essay, and the images which the book incorporates at the back. This chapel, and the reflection upon it, are examples of exceptional creativity. The Chapel serves as a perfect example of the power of space. It is a place of increased awareness, of deep theological reflection, of a loud silence and of authentic religiosity. It is a true illustration of education at its best ${ }^{15}$. Altogether, this is a good book, and I would like to congratulate the Editor for providing her readers with a text that is so thought-provoking, and so abundant in its variety.

${ }^{14}$ B. Reed, Searching for Parish Engagement Scale (SPES). A Proposal for an Empirical, Contextual and Theological Reading of a Contemporary Parish, p. 189-228.

15 H. Lombaerts, Chapel of Disclosure, translated by Brian Doyle, p. 229-236. 